\title{
We Know Which One We Prefer but We Don't Really Know Why: The Curious Case of Mixed Member Electoral Systems
}

\author{
Shaun Bowler and David M. Farrell
}

The literature on electoral systems is one of the more well developed within political science. Unlike many branches of the discipline it has successfully developed a series of commonly adopted definitions, measures and standards. Nevertheless, areas of uncertainty and disagreement exist. Using responses from a survey of scholars who study electoral systems we show where some of these areas of uncertainty lie. Intriguingly, some relate to our (collective) preference for a mixed member proportional system (MMP). MMP is the most highly regarded of electoral systems, yet it is does not seem to be the case that we have clear and consistent criteria for ranking this system so highly. Exploring this puzzle leads us to suggest topics where we, as students of electoral systems, may want to consider developing our studies further.

In present-day debates over electoral reform in developed Anglo-Saxon democracies, there are two electoral systems that feature prominently: the darling of early $21^{\text {st }}$-century electoral engineers, mixed member systems; and the system that was much spoken about in debates over electoral system design at the start of the last century, the single transferable vote (STV). ${ }^{1}$ In 1993 New Zealand's citizens voted, in a referendum, for a mixed member proportional system (MMP). In the UK, it was decided in the late 1990s that the new regional assemblies in London, Wales and Scotland (the latter a 'parliament') should be elected by MMP. Some revision of this is ongoing and at the time of writing a switch to STV for electing the Scottish parliament cannot be ruled out. ${ }^{2}$ Both MMP and STV are predominating in ongoing discussions over electoral reform across the Canadian provinces. ${ }^{3}$ And, in the US, a prominent pressure group, the Center for Voting and Democracy, is campaigning for the adoption of STV (or 'choice voting') the length and breath of the country. ${ }^{4}$

The fact that STV and the mixed member systems should be so prominent is not surprising. In a recent survey of electoral systems experts-the majority of them from Anglo-Saxon systems (namely the memberships of the relevant specialist groups of the American Political Science Association, the International Political Science Association and the UK Political Studies Association)-we found that, on the whole, the scholars generally prefer MMP ${ }^{5}$ and STV to the two main families of electoral system that have tended to predominate worldwide, namely list PR and single member plurality. MMP was the most preferred choice with STV a close second (Bowler et al. 2005). ${ }^{6}$ We can see this in a number of ways (Table 1). Our experts were asked to rank the systems. MMP won a plurality (though not a majority) of first preferences and an average ranking higher than all other systems. Using these rankings, MMP is a Condorcet winner in the sense that, in a pairwise comparison, it beats all other systems. It also wins in a Borda Count. By the same 
Table 1: Overall Rankings of Electoral Systems

\begin{tabular}{lccc} 
& Rank & Average & Number $1^{\text {st }}$ prefs \\
\hline MMP & 1 & 2.37 & 52 \\
STV & 2 & 2.60 & 38 \\
Open list PR & 3 & 3.26 & 18 \\
AV & 4 & 4.01 & 10 \\
Closed list PR & 5 & 4.17 & 9 \\
SMP & 6 & 4.67 & 21 \\
Runoff & 7 & 4.9 & 7 \\
MMM & 8 & 5.18 & 3 \\
SNTV & 9 & 6.76 & 3
\end{tabular}

Source: McDougall Trust expert survey

methods, single non-transferable vote (SNTV) is the least preferred of the electoral systems. It is tied for the smallest number of first preferences, has the lowest average ranking and is a Condorcet loser.

This article moves on from that observation with two principal aims in mind. First, we seek to establish the basis of the supposed advantages of MMP over all other systems, which, as shall be shown, proves difficult because the basis of that advantage simply is not very clear. Second, we explore areas where electoral systems research in the next generation might move forward from the old chestnut of proportionality. The map of scholarly opinion towards electoral systems has some very well-defined topography over certain issues (notably proportionality), but in other respects the map might as well include the phrase 'here be dragons', for there is much that remains unknown. Our expert survey draws out some areas of thought on electoral systems where our collective expertise is lacking; this article uses the survey to set out those areas where we seem to need more research.

There are, of course, other ways of setting out a statement of what we know and where to go next than by relying on a survey of academic experts. We could, for example, present a review of the literature or some more personal reflections on how that literature strikes us. And, good examples of both can be found in the Gallagher and Mitchell study (2005). But, studying the views of academics on their chosen subject allows us to hold up a different kind of mirror to our sense of what we have done and what we need to do. It allows us a glimpse into the gap between what we think and what we write. Essentially, in what follows, we point up some areas that we-as a scholarly community-are in agreement over, some we disagree over and, most importantly, some things that seem to shape our views on electoral systems in meaningful ways yet are not as well understood as we might like. There is, then, value in taking a small step back from the constraints of academic publishing to ask 'yes, but what do we really think-what do you like about these systems?'.

There is, of course, also the inevitable 'so what?' question. The point could be made that we might as well be surveying the views of soccer correspondents about their 
favoured soccer player, or English literature professors about which is the best of Shakespeare's plays. ${ }^{7}$ A cynic might be forgiven for wondering what is the point of this enterprise; in what respects, if any, does this advance our knowledge of the subject? We would argue, on the contrary, that there is a very real point to this enterprise, and that relates to the highly significant practical role played by electoral system experts in influencing the design of electoral systems-whether it is Edward Nanson in Australia at the turn of the last century (Farrell and McAllister 2006), or Patrick Dunleavy and Helen Margetts in British regional assemblies in the 1990s, or Louis Massicotte in Quebec today. In Nanson's case it was STV that was being proposed (unsuccessfully); in the other two instances it was MMP (successfully). If it is the case that electoral system experts are having influence over the practicalities of electoral system design, then it is of considerable interest to scholarly debate to try and get a sense of the underlying factors that cause the experts to favour one system over another.

Inevitably the questions of 'what do we like about electoral systems?' and 'where to next in the study of electoral systems?' overlap, and this article weaves its way through both questions in a rather circuitous fashion. The place to begin, however, is with what we know-and what we know is proportionality.

\section{Proportionality as a Universal Desideratum-but with Limits}

One of the properties of scholarship on electoral systems is a very clear understanding of which of the systems promote proportionality and which do not. Moreover, proportionality is seen by most as a major desirable property of electoral systems (for an exception, see Pinto-Duschinsky 1999). Table 2 demonstrates this by noting that, among the most likely criteria for evaluating electoral systems, proportionality is a clear Condorcet winner. ${ }^{8}$ The strong support for proportionality tallies with other evidence in the survey. For example, 83 per cent of respondents believe that in a society characterised by distinct cleavages and/or ethnic divisions the electoral system should be engineered to ensure that some representation of the relevant minority occurs. Similarly, 58 per cent believe that compensation schemes (awarding extra seats) are fine if they increase proportionality. Clearly, then, there is strong and consistent support for the criterion of proportionality as a desirable property of electoral systems.

There are two observations prompted by this commitment to proportionality. First, while it is a consistently stated preference and consistently stated criterion it is not entirely consistent with other opinions on electoral systems revealed by our survey: there are, in other words, some gaps. For example, in the ranking of desirable properties of electoral systems, 'helps ensure the representation of women and minorities' typically appears towards the bottom of the list. In addition the Condorcet loser in Table 2 is 'help ensure coalition government'. While coalition government is not an explicit goal of electoral systems there does exist a strong and well-known correlation between proportionality of electoral systems, multipartyism and coalition governments (for a summary, see Farrell 2001). Furthermore, while nearly half (49 per cent) of respondents believe that governments 


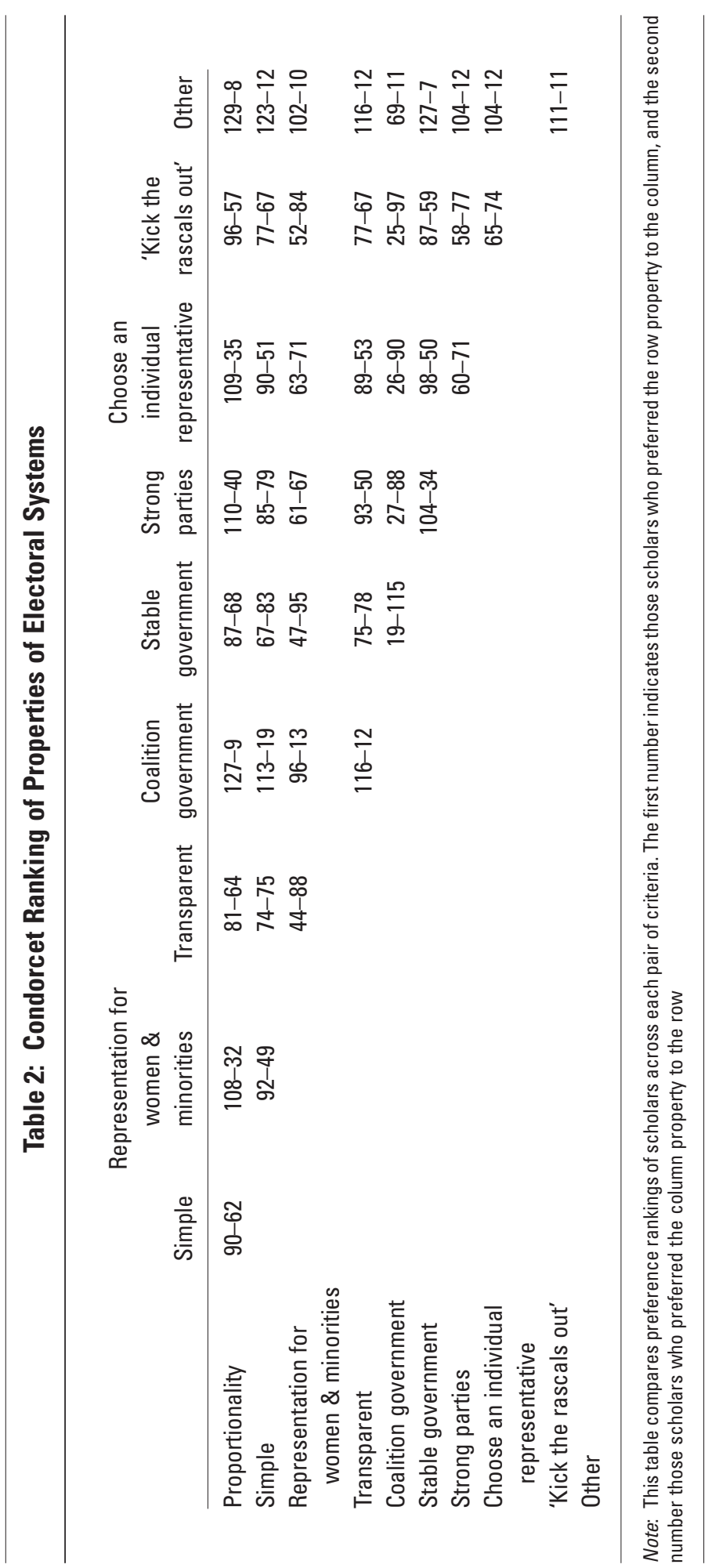




\section{Table 3: Generally Speaking, Do You Think a Government Formed by One Party, or One Formed by More than One Party, is Better at Doing the Following Things? (\%)}

\begin{tabular}{lccc} 
& $\begin{array}{c}\text { One party } \\
\text { best }\end{array}$ & $\begin{array}{c}\text { More than one } \\
\text { party best }\end{array}$ & $\begin{array}{c}\text { Both the } \\
\text { same }\end{array}$ \\
\hline Providing stability & 50 & 20 & 23 \\
Making tough decisions & 60 & 18 & 16 \\
Keeping promises & 38 & 20 & 34 \\
Doing what the people want & 12 & 49 & 24
\end{tabular}

formed by multiple parties are better than one party at reflecting what people want, the multi-partyism produced by proportionality is not an unalloyed good: in terms of providing stability in making tough decisions and, arguably, in doing what people want there is much greater support for the view that one party is best (see Table 3).

In short, the principle of proportionality may be well supported, but its actual practice would seem to leave some doubts, at least in fairly 'pure' forms. Coalition government and multi-party politics may not be a goal of PR but they are the typical consequence and so, while there may be an analytical difference between proportionality and these other features, there may not be a meaningful one in the 'real world', and this slippage may give some people pause about PR and pure PR. This slippage may explain why there is not much support for pure proportionality: the majority in our survey (79 per cent) is of the view that there should be a minimum vote threshold before a party gains seats in the legislature, with the modal (and mean) threshold being around 5 per cent. The key seems to be that proportionality should not come at the cost of effective government-but where exactly the trade-off lies is not entirely clear.

A second observation is a curiosity: list PR-which is definitively associated with proportional outcomes-does not fare as well as MMP in our ranking of systems, a point touched upon in our previous paper (Bowler et al. 2005). We can look at this in greater detail by seeing what criteria scholars identify. Here we address two sets of points that are inter-related: first we make a series of points about electoral systems and their effects; second, we make a number of points relating to the state of academic knowledge on electoral systems.

We asked our experts to rank seven electoral systems (SMP, Alternative Vote, runoff, single non-transferable vote, list, STV and MMP) on a number of traits. In Table 4 we focus on four key systems, examining how many scholars ranked a given system, in terms of a certain property, in the 'top' three, the 'bottom' three or in the middle category. In total, this produces a ranking of four electoral systems across six criteria for a total of 24 rankings. The criteria are displayed in the rough order in which these are held to be important in judging electoral systems, with proportionality as the most important criterion and cohesive parties as the least. ${ }^{9}$

As can be seen, on 12 of the 24 rankings, 80 per cent of scholars share the same assessment of a system as either being very good or very bad: for example, 81 per 
Table 4: Comparing Four Electoral Systems on a Range of Criteria

\begin{tabular}{|c|c|c|c|c|c|}
\hline \multirow[b]{2}{*}{ Criterion } & \multirow[b]{2}{*}{ Ranking } & \multicolumn{4}{|c|}{ Electoral System } \\
\hline & & SMP & STV & MMP & List \\
\hline \multirow[t]{3}{*}{ Proportionality } & Top & 5 & 97 & 89 & 100 \\
\hline & Middle & 14 & 1 & 9 & \\
\hline & Bottom & 81 & 2 & 2 & \\
\hline \multirow[t]{3}{*}{ Effective Gov } & Top & 84 & 47 & 71 & 60 \\
\hline & Middle & 7 & 24 & 16 & 5 \\
\hline & Bottom & 10 & 29 & 13 & 32 \\
\hline \multirow[t]{3}{*}{ Accountability } & Top & 85 & 52 & 62 & 47 \\
\hline & Middle & 7 & 19 & 15 & 13 \\
\hline & Bottom & 8 & 29 & 24 & 40 \\
\hline \multirow[t]{3}{*}{ Constituency service } & Top & 87 & 63 & 66 & 40 \\
\hline & Middle & 9 & 9 & 13 & 6 \\
\hline & Bottom & 5 & 27 & 21 & 51 \\
\hline \multirow[t]{3}{*}{ Minority representation } & Top & 15 & 95 & 93 & 97 \\
\hline & Middle & 14 & 4 & 5 & 2 \\
\hline & Bottom & 71 & & 2 & 1 \\
\hline \multirow[t]{3}{*}{ Cohesive parties } & Top & 76 & 42 & 84 & 81 \\
\hline & Middle & 10 & 16 & 9 & 8 \\
\hline & Bottom & 14 & 41 & 6 & 11 \\
\hline
\end{tabular}

Notes: Figures in bold represent properties where agreement is shared by 50 per cent or fewer respondents Figures in italic represent properties where agreement is shared by $60-70$ per cent of respondents

cent of scholars are of the view that SMP is not very good at delivering proportionality, while a commendable 100 per cent consider list systems as good for proportionality. There is, then, a real degree of consensus about the properties of electoral systems. It might sound a little pompous to call this 'knowledge', but these figures do show that scholars share assessments of electoral systems across a wide range of quite specific properties. And, what may well have turned the scale for MMP over list PR is that the former is more clearly associated with effective government and accountability than the latter (which may simply reflect the tendency of the longest-standing MMP system, Germany, to have two parties in government rather than multi-party coalitions).

But, for all this consensus, there are, nevertheless, areas of disagreement. The five rankings emboldened in Table 4 are the properties and systems about which scholarly opinion is more divided: either there is no clear majority, or there is at best a bare majority. Three of these relate to STV and its ability to provide effective government, accountability and cohesive parties. Two relate to divisions over the role of list systems in promoting accountability and constituency service.

Another way of looking at these proportions is to see just how certain we are as a group of scholars by looking at the maximum proportion for each property for each electoral system (i.e. the figures for good or bad, excluding the middle category). 
These trends indicate just how sure we are of our assessment: we might suggest that there is a meaningful difference between, say, 80 per cent of people sharing a particular view and 40 per cent sharing that view. For example, in terms of proportionality we see proportions of 81-100 per cent over whether a system is conducive (or not in the case of SMP) for proportionality. Similarly, for the representation of minorities the spread is 71-97 per cent, for constituency service 51-87 per cent. But, for the other properties we are less confident about the impacts. For effective government it is $47-84$ per cent, and accountability $47-85$ per cent. These proportions are revealing in a number of ways. It is abundantly clear that by now we know with some certainty-or at least with a great deal of confidence-how to accomplish proportionality and the representation of minorities.

Given the importance the electoral system specialists attach to these criteria the patterns found in this survey are meaningful ones. At the risk of being overly self-congratulatory, it is hard to think of another field within political science in which scholars have similar levels of certainty about key features of their object of study. Having said that, there are some oddities in this set of results. First, one of the more surprising things in Table 4 is the consensus-indeed the certainty-over MMP and its effects, yet, apart from the post-war German case, this system is still relatively new and unproven, and the academic literature on it is not as well established as work on other systems (the few prominent examples of academic work on this system include Shugart and Wattenberg (2000)).

It is worth looking at this gap between academic opinion and academic literature a little more closely. The conventions of academic publishing lead us to express our views in a somewhat more constrained manner than we might like and also, perhaps, to express those views with fewer doubts than we might have. Of course, not all our thoughts should be written down or would hold up to the rigours of the publishing process. Nevertheless, one of the advantages of a survey of this kind is that it allows us to see some of the difference between what we think and what we write. Needless to say, gaining some very general and manageable picture of what we write is hard to do. One admittedly crude but nevertheless revealing guide is to search for relevant terms using Google and JSTOR and use the results of that search as an indication of how much is written on key topics. Table 5 reports the results of these searches and provides some evidence consistent with the claim that, despite the flourishing of detailed scholarly work in New Zealand (e.g. Vowles et al. 1998, 2002 and 2004), there is probably not as much written-and hence known-about MMP compared to other systems. There is, also, a very considerable body of work on proportionality.

What is it that makes MMP so popular? We examine some evidence using regression models to establish more clearly what kinds of values lead people to prefer one system over another. We use a set of survey instruments that tap into values of political outcomes and processes. We then use these measures to predict both absolute and relative rankings of electoral systems.

Tables 6 and 7 present results (in two different ways) from OLS models of rankings of systems based on some evidence on preferences. In Table 6 we present fairly straightforward models that take as their dependent variable the preference ranking $(1,2,3$, etc.) given to the (named) system and predict this using responses to a set 
Table 5: Search Results for Phrases on Electoral Systems

\begin{tabular}{lrr} 
Phrase searched for & Google & $J^{S T O R}$ \\
\hline 'MMP' & 37,100 & 17 \\
'MMP' election & 599 & \\
'MMP election' & 15,500 & 14 \\
'Mixed member proportional' & 3,420 & 124 \\
'Mixed electoral system' & & \\
'STV' & 64,800 & 198 \\
'STV' election & 594 & 46 \\
'STV election' & 57,300 & 55 \\
'Single transferable vote' & 21,600 & 2,563 \\
'List PR' & 8,450 & 1,062 \\
'List proportional representation' & 625,000 & 14 \\
'Proportional representation' & $2,010,000$ & \\
'PR' election & 649 & \\
'PR electoral system' & & \\
The phrase 'MMP' election was searched as MMP in quotation marks space, then the word election. Similarly, & \\
phrase 'STV' election was searched as STV in quotation marks space, then the word election. Google/JTOR
\end{tabular}

of questions about democratic values and processes. To keep with the intuition of ranking the most preferred systems ' 1 ' (for $1^{\text {st }}$ ), the dependent variable is one where low numbers mean something is more highly rated. Table 6 provides evidence that some normative values are tied to evaluations of electoral systems. There is a straightforward component to the preferences for electoral systems: for example people who prefer one-party government prefer SMP (Table 6 column 1) and dislike list PR (Table 6 column 5). In terms of support for MMP in particular, then, we should note that among the values that generate support for MMP are attitudes towards political parties. Column 3 of Table 6 shows that higher rankings to MMP are given by people who think parties should work towards agreement rather than emphasise clear differences. Oddly, this same opinion generates support for SMP. Seeing parties as central actors also helps generate support for MMP (just, at the .10 level), while this depresses support for STV.

Table 7 is slightly more complicated in that it looks at the difference in preference rankings of pairs of systems: a negative number means that the first-named system is rated more highly (e.g. a $1^{\text {st }}$-ranked system minus a $6^{\text {th }}$-ranked system); a positive number means the reverse. Of particular interest here are the comparisons between MMP and both the list systems of proportional representation and STV (the first three columns of this table). Again, the importance of having parties generate consensus (the first row of Table 7) is an important, if not the most important, value that generates the preference for MMP over its closest rival systems. Other factors do have an impact-most notably the value in having one person or several 


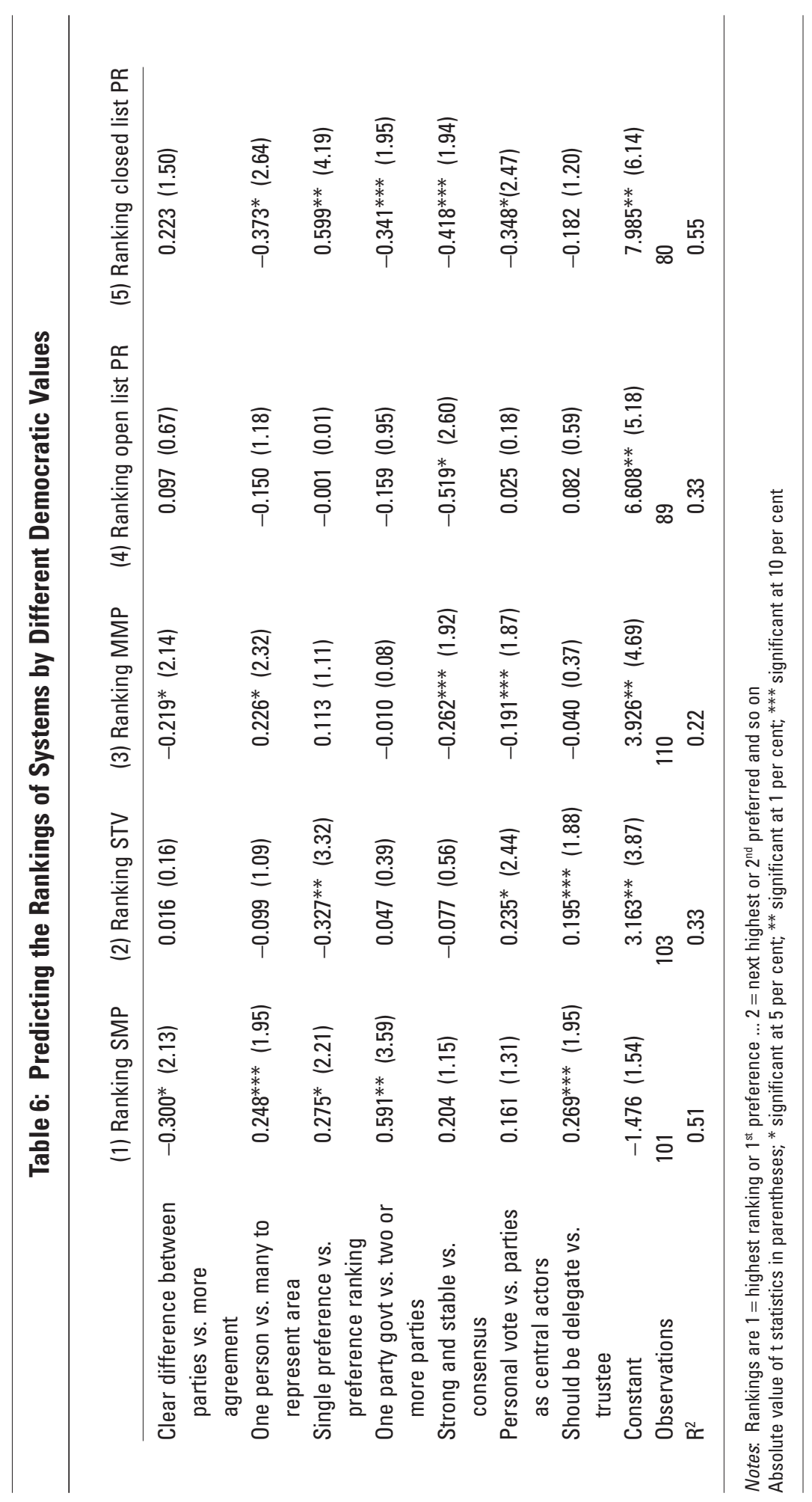




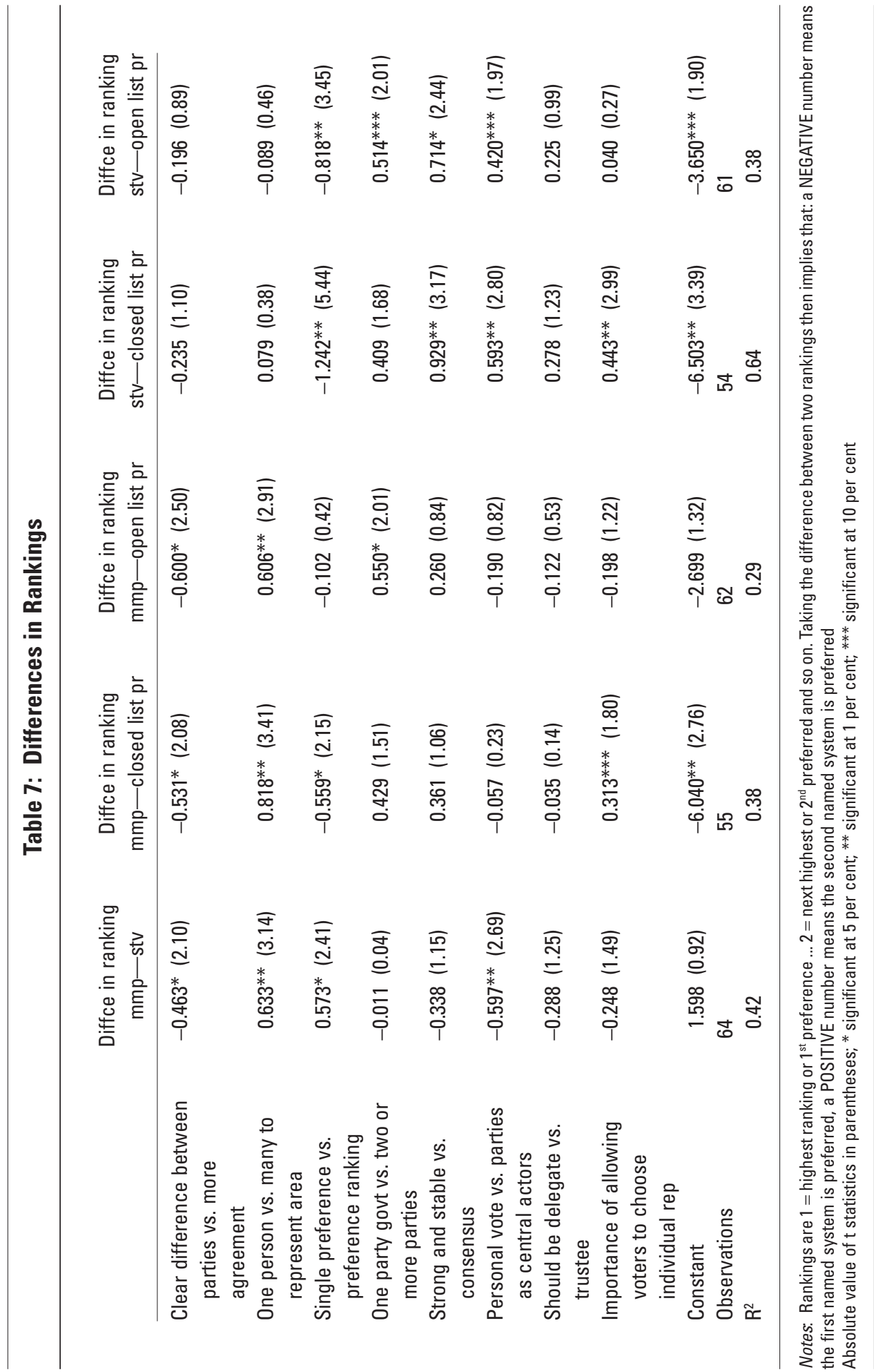


representing an area. That is, presumably the single district component of MMP means it scores for some over STV and list systems. What we see here is that models predicting the evaluation of MMP perform worse than other models: the whole parameters are smaller, fewer pass conventional thresholds of statistical significance and measures of fit $\left(\mathrm{R}^{2}\right)$ are lower.

The patterns of support are open to a variety of interpretations. Our interpretation of the overall patterns in these tables is the following: even though MMP may be relatively highly rated, it is not clear why this is so. As experts we have quite clearly established and fairly well-defined preferences over two sorts of institutions-SMP and list systems-but have much less well-defined preferences over MMP and STV. The kinds of things that drive us to prefer these systems are, moreover, not well established in the literature. We can show this in the case of MMP, where to the extent that we can actually identify any values associated with support for this system, it is not entirely clear how these should fit. For instance, one reason for liking MMP is that we value consensus over clear differences (Table 7 cols 1 and 2 row 1). But is consensus a product of MMP? And, if so, how? It may be true for the German case but is it also true for other mixed member systems such as New Zealand's, or, indeed, Russia's mixed member majoritarian system? Another value that drives support for MMP seems to be a dislike of asking voters for preference rankings per se and a liking for one representative per district (Table 7 rows 2 and 3). But these may not be well-established properties of MMP. It is not clear, for example, how much of a difference having ' $a$ ' representative makes to German voters. In short, then, the preference for MMP among our sample of experts is unmistakable, but the reasons for that preference, and for preferring MMP over list systems or STV, are not nearly so clear cut. ${ }^{10}$

\section{Proportionality, and Then What?}

It is clear that we are not very certain about our knowledge on some key issues relating to electoral systems and governance: we know how to advise new democracies on how to achieve a proportional result, but we do not know how to accomplish things beyond that. Part of this probably reflects the fact that we are not entirely in agreement on some key issues over what should matter in a systemespecially regarding the role of parties. Parties, we agree, should reflect opinion and important divisions in society, but they should also exercise power. At that point we are-as a group—not so clear. Table 8 shows responses from some assessments of the trade-offs implied by electoral systems on a seven-point scale. The table reports the distribution of responses (percentages of respondents marking each of the seven points) as well as the mean ranking.

As can be seen, by and large our assessments put us-as a group-somewhere in the middle on each of the scales. We shade a little towards wanting clear difference between parties, and lean a little more strongly towards liking political parties and, also, favouring some idea of consensus. But all of these replies cluster in the middle of the scales. To be sure, some of that clustering around the mid-point is part and parcel of any scale like this, but what we do not see are the kinds of definite opinions that are visible in Table 4. Nor is there a bimodal distribution of opinions; rather, what we see are responses that cluster towards the middle of the scale. 


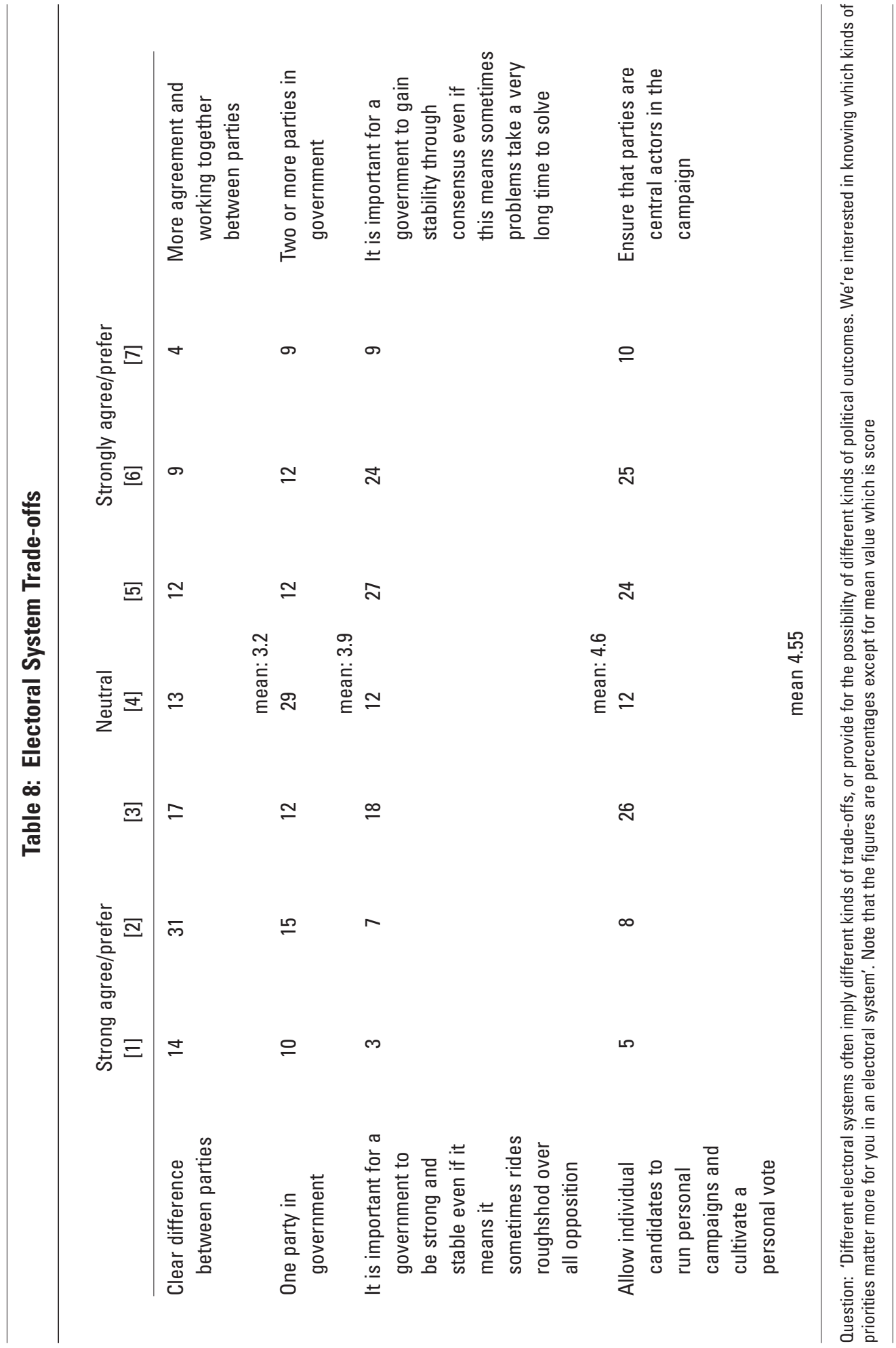




\section{Discussion}

To paraphrase Donald Rumsfeld, there are things we know we don't know and things we don't know we don't know. In this article we have pointed to some of the things that we know we don't know. We know all we could possibly need to know about proportionality but we don't know very much about governance. As dismissive as that sounds, we should be careful to underscore the very real accomplishment of the field of electoral studies: there is a great deal of consensus on a number of key issues. This kind of accomplishment is unusual within political science as a whole and we should recognise that accomplishment even as we consider 'where next?' There are some issues that we do seem to think are important-and possibly ones that colour our overall assessments of electoral systems-yet we probably know very little about. If, as a field of study, we were to break free from the fixation with proportionality and commit the Grofman 'heresy' of giving similar attention to other areas (Grofman 1999; see also Shugart 2005), what other areas might we select for examination?

Many of the opinions we picked up in our survey seem to reflect an underlying sense of the conditional nature of electoral system effects. Some respondents told us that the answer to many questions was 'it depends', and this led a few to refuse to complete the survey. Despite this conditionality, and in the spirit of scholarly co-operation that characterises much of this field, many still went ahead and answered the questions as best they could. This 'it depends' answer, we think, is fair enough, but having said that it does not appear much in the literature. Otherwise, surely we would know more what the effects depend upon. Part of the reason for that may be because some electoral systems-most notably SMP and list PR-have quite pronounced effects and so there may be little need to qualify or hedge. But other systems, such as MMP or STV, are not so cut and dried, and conclusions about these systems may require more qualification or, perhaps, just more context. And, with that in mind, it is probably worth moving our attention to these other systems in order to establish some of the conditions under which electoral systems have given effects.

Bernie Grofman, for example, has for some time talked of electoral systems as 'embedded institutions' whose effects are likely to depend on other institutions and actors (Grofman et al. 1999; Bowler and Grofman 2000). To be sure, Grofman is not alone in this. In a study of the varieties of Westminster which foreshadowed some subsequent findings to the effect that Westminster systems do not always produce 'Westminster' patterns, the doyen of British electoral systems research, David Butler, noted that 'one should be sceptical about attributing fixed qualities to electoral systems ... Although electoral systems are among the most quantifiable of political phenomena, they do not conform to mechanistic rules' (Butler 1983, 59; see also Blau 2003). A next step is probably to produce a better developed sense of what the conditions are that help magnify or diminish electoral system effects.

Beyond establishing the conditions of effects we also seem to be relatively ill informed about, but nevertheless influenced by, our sense of what happens after the election is over. We don't really know much about what we consider an optimum number of parties for governability, but do seem to have the general sense 
that having lots of small parties (below 5 per cent) is too many and two might be too few. Obviously we are unlikely to arrive at a point estimate ('2.256') of the 'ideal' number of parties no matter what; especially since we might well be moving to elaborate more the conditional or embedded nature of electoral systems. But developing some sense of range might be good. Perhaps a better phrasing of what we are driving at is the following. Electoral studies might benefit from considering more of the issues 'downstream' from the election to take on board some of the lessons of coalition studies and also of governability more broadly. It seems likely that electoral systems provide incentives for those engaged in coalitional games, and maybe too much proportionality and possibly too much of a party-centred approach may be features that need to be leavened.

Again, this point can be read as underscoring some existing currents within electoral studies work. Recent work by Arend Lijphart (1999) and G. Bingham Powell (2002) on the political consequences of proportionality, for example, have started to address what happens after the election is over. Others too have pointed out that it is time to move on from our fetish for proportionality (see, e.g., Baker 1996). But, this survey evidence clearly shows that with so many of us agreeing so thoroughly on proportionality and how it is achieved, it is hard to see what there is new to say on the topic. It is an unambiguous signal that it is time to move on and take the hints others have made more seriously. ${ }^{11}$

In sum, perhaps what seems to be our collective hunch that MMP is the best of both worlds'12 is right. But, there is a deal of difference between having a conjecture and actually knowing something. Luckily, the electoral studies field is one thathistorically-has made great strides in moving us from conjecture to knowledge.

\section{About the Authors}

Shaun Bowler, Department of Political Science, University of California, Riverside, CA, USA, email: shaun.bowler@ucr.edu

David M. Farrell, School of Social Sciences, University of Manchester, Manchester M13 9PL, UK, email: david.farrell@manchester.ac.uk

\section{Notes}

An earlier version of this article was delivered at the annual meeting of the American Political Science Association, Washington DC, August-September 2005. Co-authorship is equal. Support for the expert survey came from the McDougall Trust, London (www.mcdougall.org.uk), which is not responsible for errors or misinterpretations of the data presented here. We are grateful to Robin Pettitt for his research support, and to the participants at the APSA panel, our three referees, and Adrian Blau, Michael Gallagher, Chris Pierson and Matt Shugart for helpful comments and feedback. The usual disclaimer applies.

1. This point may or may not be generalisable outside of the Anglo-Saxon cases.

2. The recent switch to STV for electing Scottish local government councillors (which may also occur in Wales) has clearly played a role in raising the profile of STV as witnessed by the ongoing deliberations of the Arbuthnott Commission.

3. See, for instance, the deliberations of British Columbia's Citizens' Assembly on Electoral Reform (http://www.citizensassembly.bc.ca/public), which recommended that the province shift from SMP to STV. Its recommendation narrowly failed to meet the required 60 per cent threshold in a referendum in 2005. The referendum will be re-run in 2007. More generally, see Cross (2005). 
4. http://www.fairvote.org/.

5. From here on out, we refer to mixed member systems by the acronym MMP (mixed member proportional). While we recognise that mixed member systems come in many forms, our survey revealed quite a deal of misunderstanding, especially regarding the distinction between the (German) MMP variant and the far more common MMM (mixed member majoritarian, also known as 'parallel') variant-this finding in itself rather revealing. For further discussion on mixed member systems generally, see Shugart and Wattenberg (2000).

6. These are the key specialist groups of the three political science associations, and they comprise a mix of established political science professors, graduate students and members of relevant practitioner groups. We fully realise that there are limitations with this sampling framework, principally: (i) knowledge of, and expertise on electoral systems vary across the membership; and (ii) not all electoral system experts are members of these groups (and certainly many non-English-speaking political scientists are excluded-hence our reference to an Anglo-Saxon emphasis). But, the fact of the matter is that these are the most representative groups of scholarly expertise in the field of electoral system research. Every effort was made to clean out of the population members who are not scholars (such as publishers or representatives of polling companies). This resulted in a total population, across the three groups, of 547. If we accept this as an approximation of the total population of electoral systems experts, our response rate $(\mathrm{N}=170)$ of 31 per cent is pretty reasonable.

7. This very point was made by one of our referees.

8. In our previous paper we demonstrated how proportionality is also the most preferred of all the criteria using other counting measures, such as number of first preferences, or average ranking (Bowler et al. 2005).

9. There is some slippage here in that this list approximates but does not replicate the list of criteria. See Bowler et al. (2005) for details.

10. One of the hunches we have as a consequence of this work is that we tend to think of electoral systems in terms of examples and ideal-types, and this may be especially so with the newer family of mixed member systems. So, our view of MMP may well be shaped by our knowledge of Germany. What our survey did not help us get a handle on was what are the most influential case examples of particular electoral systems at work.

11. Someone once suggested that street buskers be allowed to perform but only after taking an exam to see if they were really entertaining. The exam for guitarists was to be made especially difficult. It was only by this way that we could rid our cities of the scourge of whiny versions of 'Streets of London'. Perhaps something similar might be in order for the review process as it applies to papers on proportionality.

12. Although we should be careful to note that Shugart and Wattenberg do add a question mark at the end of their title.

\section{Bibliography}

Baker, J. (1996) 'Fair representation and the concept of proportionality', Political Studies, 44, 733-737.

Bingham Powell, G. (2002) Elections as Instruments of Democracy (New Haven, CT: Yale University Press).

Blau, A. (2003) 'The comparative study of electoral systems: Time, space, and the translation of votes to seats', mimeo.

Bowler, S., Farrell, D. and Pettitt, R. (2005) 'Expert opinion on electoral systems: So which electoral system is "best"?', Journal of Elections, Public Opinion and Parties, 15, 3-20.

Bowler, S. and Grofman, B. (eds) (2000) Elections in Australia, Ireland, and Malta under the Single Transferable Vote: Reflections on an Embedded Institution (Ann Arbor, MI: University of Michigan Press).

Butler, D. (1983) 'Variants of the Westminster model', in V. Bogdanor and D. Butler (eds), Democracy and Elections: Electoral Systems and Their Political Consequences (Cambridge: Cambridge University Press), 46-61.

Cross, W. (2005) 'The rush to electoral reform in the Canadian provinces: Why now?', Representation, 41, 75-84.

Farrell, D. (2001) Electoral Systems: A Comparative Introduction (London/New York: Palgrave).

Farrell, D. and McAllister, I. (2006) The Australian Electoral System: Origins, Variations and Consequences (Sydney: University of New South Wales Press).

Gallagher, M. and Mitchell, P. (eds) (2005) The Politics of Electoral Systems (Oxford: Oxford University Press). 
Grofman, B. (1999) 'SNTV, STV, and single-member district systems: Theoretical comparisons and contrasts', in B. Grofman, S.-C. Lee, E. Winckler and B. Woodall (eds), Elections in Japan, Korea, and Taiwan under the Single Non-transferable Vote: The Comparative Study of an Embedded Institution (Ann Arbor, MI: University of Michigan Press), 317-336.

Grofman, B., Lee, S.-C., Winckler, E. and Woodall, B. (eds) (1999) Elections in Japan, Korea, and Taiwan under the Single Non-transferable Vote: The Comparative Study of an Embedded Institution (Ann Arbor, MI: University of Michigan Press).

Lijphart, A. (1999) Patterns of Democracy: Government Forms and Performance in Thirty-six Countries (New Haven, CT: Yale University Press).

Pinto-Duschinsky, M. (1999) 'Send the rascals packing: Defects of proportional representation and the virtues of the Westminster model', Representation, 36, 117-126.

Shugart, M. (2005) 'Comparative electoral systems research: The maturation of a field and new challenges ahead', in M. Gallagher and P. Mitchell (eds), The Politics of Electoral Systems (Oxford: Oxford University Press), 3-27.

Shugart, M. and Wattenberg, M. P. (eds) (2000) Mixed-Member Electoral Systems: The Best of Both Worlds? (Oxford: Oxford University Press).

Vowles, J., Aimer, P., Banducci, S. and Karp, J. (eds) (1998) Voters' Victory? New Zealand's First Election under Proportional Representation (Auckland: Auckland University Press).

Vowles, J., Aimer, P., Karp, J., Banducci, S., Miller, R. and Sullivan, A. (2002) Proportional Representation on Trial: The 1999 New Zealand General Election and the Fate of MMP (Auckland: Auckland University Press).

Vowles, J., Aimer, P., Banducci, S., Karp, J. and Miller, R. (eds) (2004) Voters' Veto. The 2002 Election in New Zealand and the Consolidation of Minority Government (Auckland: Auckland University Press). 